\title{
THE LARVA OF DINOPONERA (HYMENOPTERA: FORMICIDAE: PONERINAE)
}

\author{
By George C. Wheeler and Jeanette Wheeler* \\ Adjunct Research Associates, \\ Desert Research Institute \\ Reno, Nevada
}

In the Genera Insectorum Emery ends his account of the genus Dinoponera laconically thus: "C'est le géant des Formicides." Zahl (1959) referred to Dinoponera gigantea as "the world's largest ant" and embroidered his account with excellent photographs of eggs, larvae, cocoons, a male and workers; there are no queens in this genus. Kempf in his 1971 revision of the genus gives the length of the worker of this species as " $30 \mathrm{~mm}$ and over."

The generic name is derived from the Greek deinos terrible, fearful, and the generic name Ponera. After reading Zahl's 1939 and 1959 articles we readily agree that the name is most appropriate because of the large size, the prominent toothed mandibles, the black color and the potent sting.

The range of the genus is almost limited to Brazil, but it does spill over into adjacent Peru, Bolivia and Argentina.

Our description (1952:607) of the genus and D. mutica were based on one tattered integument (probably of Mann's [1916:409] larva) and an unlabeled photograph. The latter was probably made by Mann and used as the basis for his description and drawing (1916: Pl. 7, Fig. 55) of an "immature (?) larva $13 \mathrm{~mm}$ long." Our Fig. 4 (1952: Pl. II) is a reconstruction.

The larva of the world's largest ant certainly deserves better treatment than we were able to give it at that time but are now able to render it, thanks to the kindness of Dr. William Overal in Belém, Pará. He supplied us with eggs, larvae of 4 sizes, pupae, cocoons and workers of $D$. gigantea.

\footnotetext{
*Address for correspondence: 3358 NE 58th Avenue, Silver Springs, Florida 32688 Manuscript received by the editor July 22, 1985
} 


\section{Genus Dinoponera Roger}

Revised CHARACTERIZATION. Profile pogonomyrmecoid (i.e., diameter greatest near the middle of abdomen, decreasing gradually toward anterior end and more rapidly toward posterior end, which is rounded; thorax more slender than abdomen and forming a neck, which is curved ventrally). Body with numerous (114-160) mammiform tubercles, each with 2-25 short simple hairs; body hairs lacking elsewhere. Cranial hairs lacking. Mandible dinoponeroid (i.e. narrowly subtriangular in anterior view; apical portion curved posteriorly; with or without medial teeth.)

\section{Dinoponera gigantea Perty}

Mature WORKER LARVA. Fig. 1. Length (through spiracles) 18.8 $\mathrm{mm}$; removed from cocoon, contracted $20.5 \mathrm{~mm}$; removed from unfinished cocoon, not contracted $23.6 \mathrm{~mm}$. Profile pogonomyrmecoid, with or without lateral longitudinal welts; with 116 mammiform tubercles distributed as follows: T2, T3 and AIX with 8 tubercles each, T1 and AI-AVIII with 10 tubercles each, AX with 2; each tubercle with 2-25 short simple smooth hairs; ventral pairs of tubercles smaller than the others and with fewer hairs. Leg vestiges present. Anus posteroventral. Somites distinct. Spiracles small. Integument densely spinulose, the spinules rather large and arranged in short to long rows, longest anteroventrally. Body hairs lacking except on tubercles. Cranium transversely subelliptical; integument rugulose; a few rugae bearing minute spinules or papillae. Antennae small; with 3 sensilla each. Head hairs lacking except on venter of labium; integument with about 50 sensilla. Labrum trapezoidal; anterior surface with ventrolateral bosses, each bearing about 24 sensilla; ventral surface densely spinulose, the spinules longer laterally; each half with 1 isolated and 2 contiguous sensilla; entire posterior surface densely spinulose, the spinules rather long and in numerous rather long subtransverse rows, the spinules so long and the rows so close together that the spinules overlap; each half with 4 sensilla in a longitudinal row near middle. Mandible large, apical and subapical teeth heavily sclerotized and curved posteriorly; with a small medial blade bearing a medial tooth; posterior surface spinulose, the spinules minute and isolated or in short rows. Maxilla large and bulging laterally; apex paraboloidal, entire surface densely covered with isolated spinules, the spinules longer ventrally; palp 

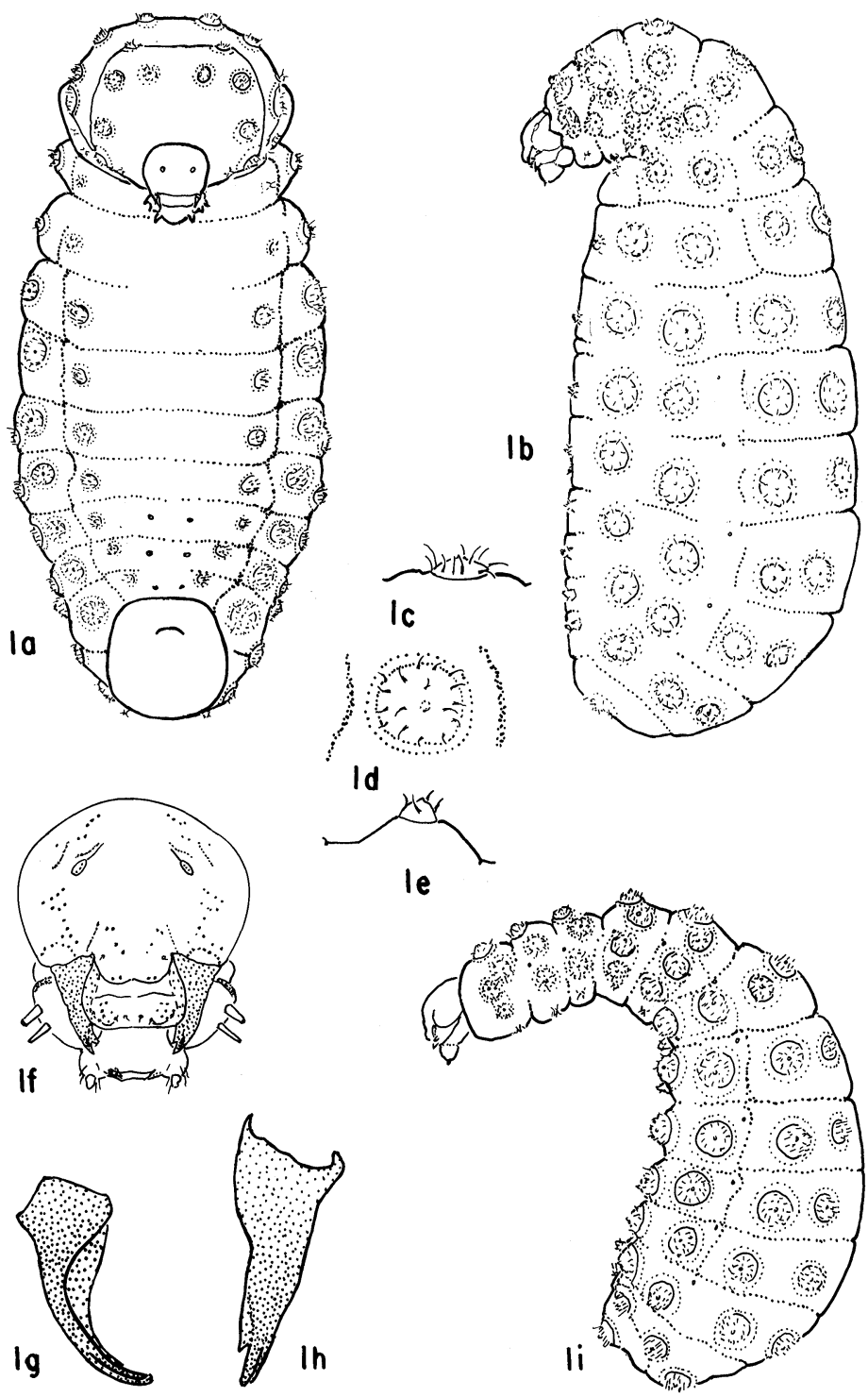

Figure 1. Fourth instar larva. a, Larva (removed from cocoon, contracted) in ventral view, $\times 4.5$; $b$, larva (removed from unfinished cocoon, not contracted) in side view, $\times 4.5$; c, lateral tubercle in side view, $\times 9$; $d$, lateral tubercle in surface view, $\times 9$; $\mathrm{e}$, ventral tubercle in side view, $\times 9$; $\mathrm{f}$, head in anterior view, $\times 16$; $\mathrm{g}$, left mandible in lateral view, $\times 37$; $h$, left mandible in anterior view, $\times 37$; i, early fourth instar larva in side view, $\times 4.5$. 


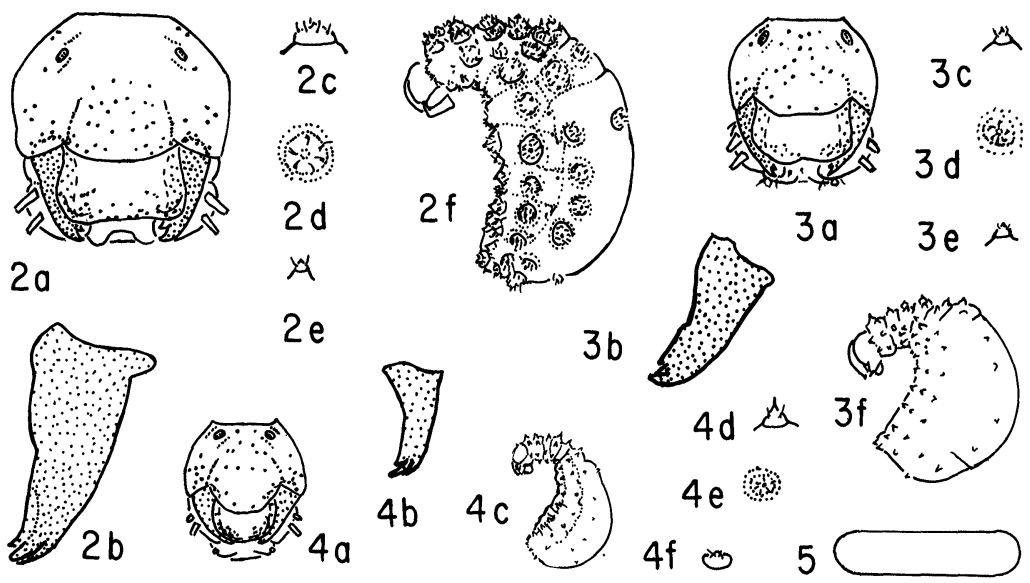

Figure 2. Third instar larva. a, Head in anterior view, $\times 16$; $b$, left mandible in anterior view, $\times 37$; c, lateral tubercle in side view, $\times 9$; $d$, lateral tubercle in surface view, $\times 9$; e, ventral tubercle in side view, $\times 9$; $f$, larva in side view, $\times 4.5$, Figure 3 . Second instar larva. a, Head in anterior view, $\times 16$; $b$, left mandible in anterior view, $\times 37$; c, lateral tubercle in side view, $\times 9$; $d$, lateral tubercle in surface view, $\times 9$; e, ventral tubercle in side view, $\times 9$; $f$, larva in side view, $\times 4.5$. Figure 4. First instar larva. a, Head in anterior view, $\times 16$; $b$, left mandible in anterior view, $\times 37$; c, larva in side view, $\times 4.5$; $\mathrm{d}$, lateral tubercle in side view, $\times 9$; e, lateral tubercle in surface view, $\times 9$; , ventral tubercle in side view, $\times 9$. Figure 5. Egg, $\times 4.5$.

digitiform with 5 ( 2 with a spinule each, 1 encapsulated, 2 small and peg-like) apical sensilla; galea digitiform with 2 apical sensilla. Labium with the anterior surface densely spinulose, the spinules isolated or in rows and small to large; with about 6 unbranched smooth hairs, $0.08-0.1 \mathrm{~mm}$ long on each ventrolateral area; palp paxilliform with sensilla similar to those on maxillary palp; opening of sericteries wide and salient with a sclerotized bar on each lateral surface. Hypopharynx densely spinulose, the spinules long and in numerous arcuate anastomosing rows, the rows so close together that the spinules overlap.

THIRD INSTAR LARVA. Fig. 2. Length (through spiracles) about $11 \mathrm{~mm}$. Similar to mature larva except as follows. Thorax more slender and gaster more swollen; neck includes T1-T3 and AI and AII. Tubercles on dorsum of AVI-AVIII reduced to a ring of hairs. Six differentiated somites. Cranium subhexagonal; 1.4 times as broad as long; middle 0.4 of dorsal border flat. Antennae near 
occipital border. Anterior surface of labrum with short rows of minute spinules ventrally, ventral surface with about 6 sensilla. Opening of sericteries a small hole on ventral surface of labium.

SECOND INSTAR LARVA. Fig. 3. Length (through spiracles) about $7.3 \mathrm{~mm}$. Similar to third instar larva except as follows. Only 8 tubercles on AVII and 6 on AIX; tubercles with center cone-shaped. Cranium with occipital surface flat for half its width. Labrum feebly bilobed; posterior surface with minute spinules. Labium with ventral border trilobed; palp a low knob.

FirST INSTAR LARVA. Fig. 4. Length (through spiracles) about $3.3 \mathrm{~mm}$. Similar to third instar larva except as follows. Tubercles reduced to 6 each on AVII and AVIII and 2 each on AI and AX; tubercles surmounted by a sharp-pointed cone. Integumentary spinules minute. Cranium 1 1/3 times as broad as long; occipital border concave, with a prominent sclerotized horn on each occipital angle. Labial palp a slight elevation.

EGG. Fig. 5 . 2.16 by $0.5 \mathrm{~mm}$, ellipsoidal, straight-sided.

Material studied: 8 larvae and 2 eggs from Brazil, courtesy of Dr. William Overal.

\section{LITERATURE CITED}

Emery, C. 1911. Genera Insectorum, Fam. Formicidae, Subfam. Ponerinae. Fasc. 118, 125 p., 5 pl.

KempF, W. W. 1971. A preliminary review of the ponerine ant genus Dinoponera Roger. Studia Entomol. 14: 369-394.

ManN, W. M. 1916. The Stanford Expedition to Brazil 1911, John C. Branner, Director. The ants of Brazil. Bull. Mus. Comp. Zool., Harvard Coll. 60: 399-490, $7 \mathrm{pl}$.

Wheeler, G. C. AND Jeanette Wheeler. 1952. The ant larvae of the subfamily Ponerinae. Amer. Midland Nat. 48: 111-114, 604-672.

Zahl, P. A. 1939. To the Lost World. Alfred A. Knopf, New York. 268 p.

ZAHL, P. A. 1959. Giant insects of the Amazon. National Geog. Mag. (May) 115: 632-669. 

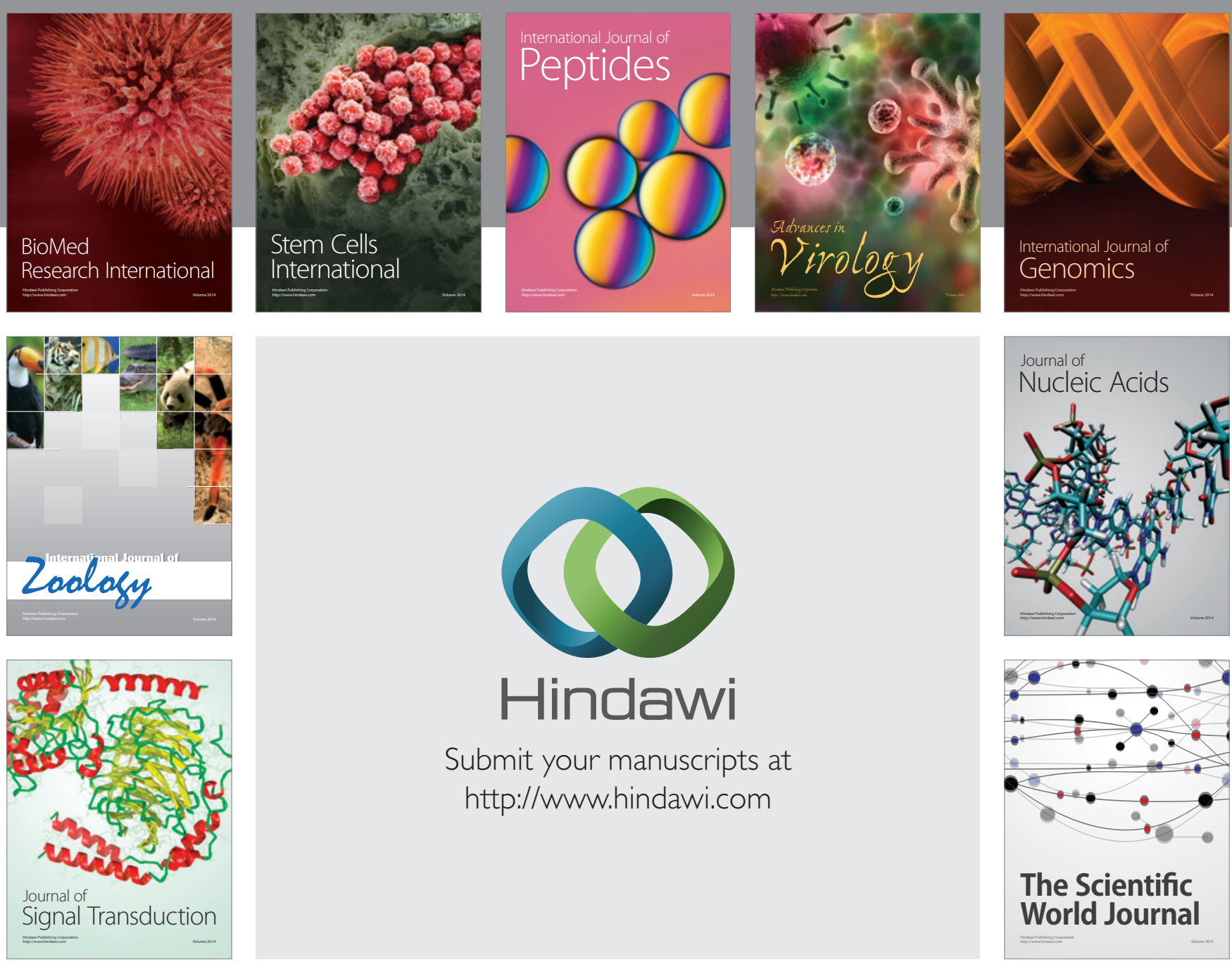

Submit your manuscripts at

http://www.hindawi.com
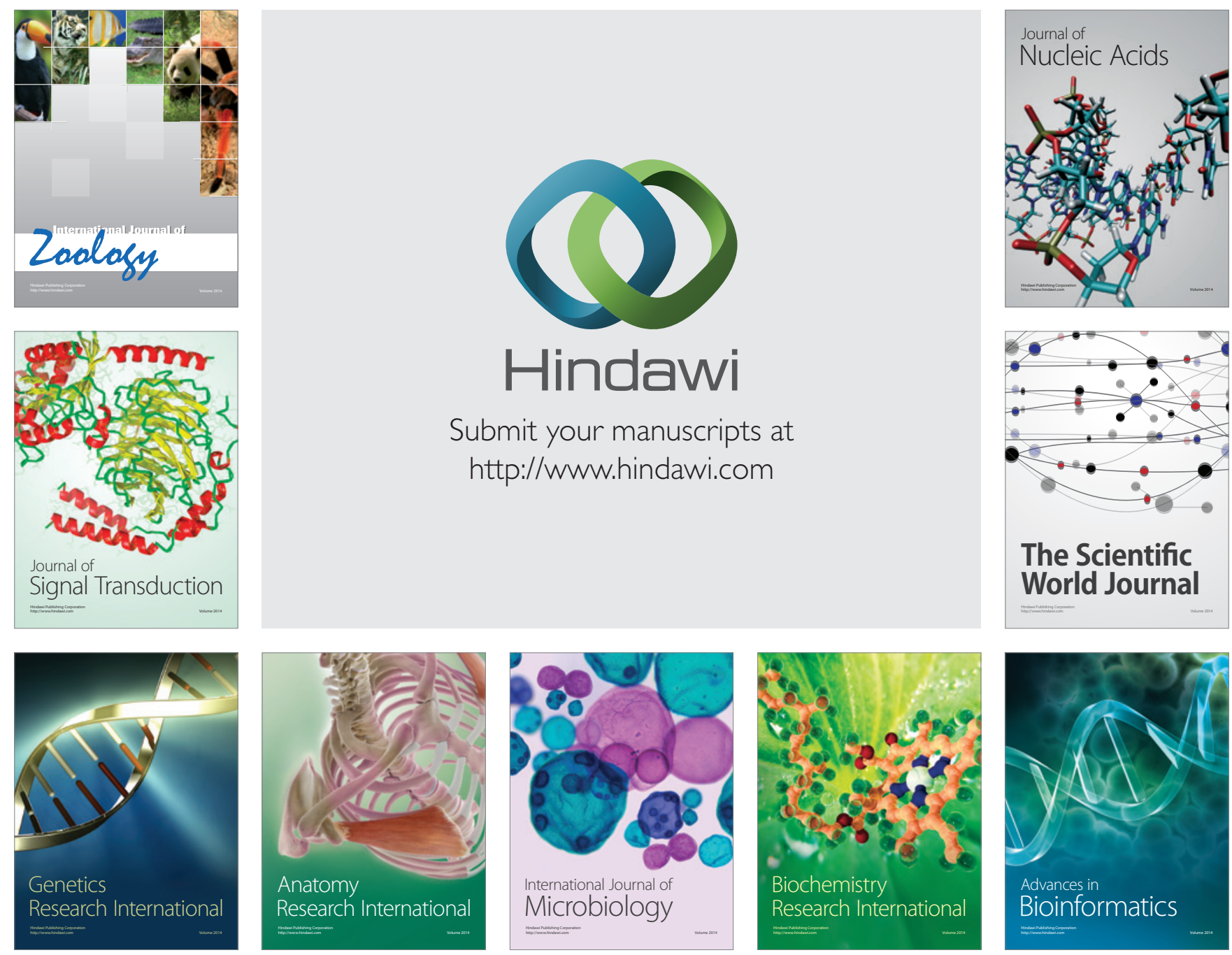

The Scientific World Journal
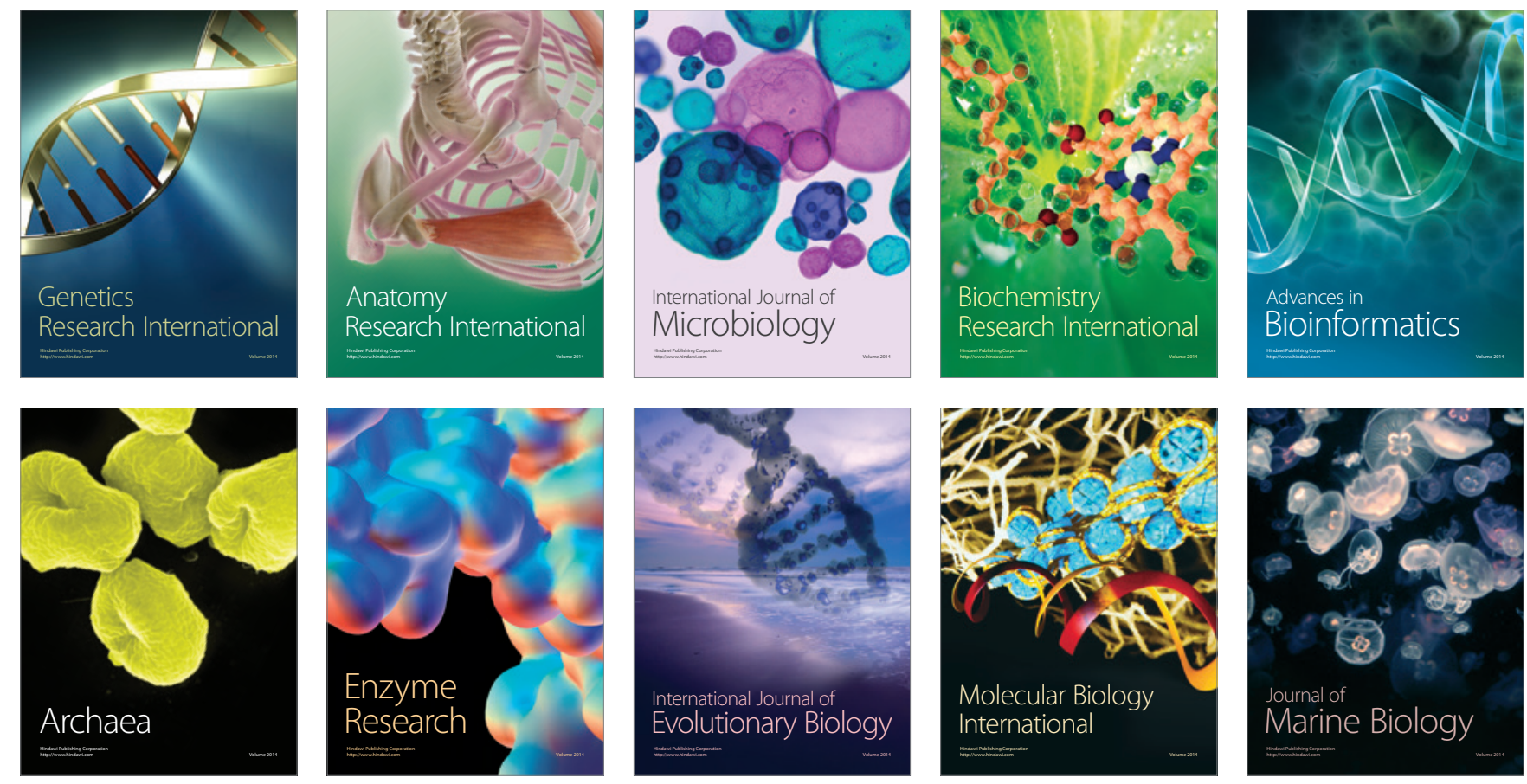